\title{
Selective inhibition of nuclear export: a promising approach in the shifting treatment paradigms for hematological neoplasms
}

\author{
Suresh Kumar Balasubramanian ${ }^{1}$, Asfar S. Azmi ${ }^{1}$ and Jaroslaw Maciejewski ${ }^{2}{ }^{\text {网 }}$ \\ (c) The Author(s) 2021
}

Novel targeted therapeutics alone or in rational combinations are likely to dominate the future management of various hematological neoplasms. However, the challenges currently faced are the molecular heterogeneity in driver lesions and genetic plasticity leading to multiple resistance pathways. Thus, progress has overall been gradual. For example, despite the advent of targeted agents against actionable drivers like FLT3 in acute myeloid leukemia (AML), the prognosis remains suboptimal in newly diagnosed and dismal in the relapsed/refractory (R/R) setting, due to other molecular abnormalities contributing to inherent and acquired treatment resistance. Nuclear export inhibitors are of keen interest because they can inhibit several active tumorigenic processes simultaneously and also synergize with other targeted drugs and chemotherapy. XPO1 (or CRM1, chromosome maintenance region 1) is one of the most studied exportins involved in transporting critical cargoes, including tumor suppressor proteins like p27, p53, and RB1. Apart from the TSP cargo transport and its role in drug resistance, XPO1 inhibition results in retention of master transcription factors essential for cell differentiation, cell survival, and autophagy, rendering cells more susceptible to the effects of other antineoplastic agents, including targeted therapies. This review will dissect the role of XPO1 inhibition in hematological neoplasms, focusing on mechanistic insights gleaned mainly from work with SINE compounds. Future potential combinatorial strategies will be discussed.

Leukemia (2022) 36:601-612; https://doi.org/10.1038/s41375-021-01483-z

\section{INTRODUCTION}

Despite the progress made in identifying the most common molecular lesions in various hematological malignancies, the frequent lack of a key driver mutation, the complex interplay when multiple lesions are present, and molecular heterogeneity within coexisting sub-clones constitute a challenge for targeted therapeutics. For instance, despite drugs against actionable drivers in acute myeloid leukemia (AML) [1], the meaningful outcomes as seen with imatinib in chronic myeloid leukemia (CML) have not been replicated with regard to the long-term prognosis of new or refractory AML cases [2]. Additional targeted agents or other rationally applied drugs in combinatorial regimens constitute one of the most appealing approaches to overcoming treatment challenges. In this context, among various potential novel strategies, nuclear export inhibition is of particular interest. XPO1 inhibitors, with their inhibitory effects on various tumorigenic pathways, synergize with multiple antineoplastic agents used in hematological neoplasms and other cancers. Nuclear export as a therapy target has been a subject of basic and clinical research for a decade now. We explore its role as a backbone for combination therapeutic strategies. While preclinical studies in nuclear export inhibition have been successfully translated to bedside medicine in multiple myeloma (MM) and non-Hodgkin lymphoma (NHL), the same milestones have not been achieved in MDS and AML. Hence, we will focus more on the preclinical rationale for the combination strategy using XPO1 inhibition in MDS and AML specifically.

Nucleocytoplasmic shuttling and the role of XPO1 in cancer Nucleocytoplasmic shuttling is critical for the homeostasis of eukaryotic cells $[3,4]$ maintaining protein balance across the nucleus and cytoplasm essential for cell survival and death [4]. Neoplastic cells are heavily dependent on this process for their substantial metabolic demand. The ability to alter the nucleocytoplasmic traffic of essential cargo proteins creates opportunities to target various unique pathways implicated in carcinogenesis.

Nuclear pore complexes are highly specialized structures embedded in the nuclear envelope and help transport various payloads across both directions [5]. Some are by simple diffusion, whereas others need an energy-dependent active transfer fueled by the RAN-GTPase system [4] (Fig. 1A). There are specialized protein receptors identified as importins and exportins maintaining the nucleo-cytoplasmic traffic. These receptors belong to the karyopherin family, which includes a broader subfamily of importin (IPO) a and IPO $\beta$. The exportin XPO1 (exportin 1)/ CRM1(chromosome region maintenance 1 ), one of the most studied with respect to its function and implication in carcinogenesis, is classified under importin $\beta$ superfamily of karyopherins $[6,7]$. This shuttling process is navigated by recognizing specific

\footnotetext{
'Department of Oncology, Wayne State University School of Medicine, Detroit, USA. ${ }^{2}$ Translational Hematology and Oncology Research, Cleveland Clinic, Cleveland, USA. 凶email: maciejj@ccf.org
}

Received: 7 September 2021 Revised: 4 November 2021 Accepted: 16 November 2021

Published online: 29 January 2022 


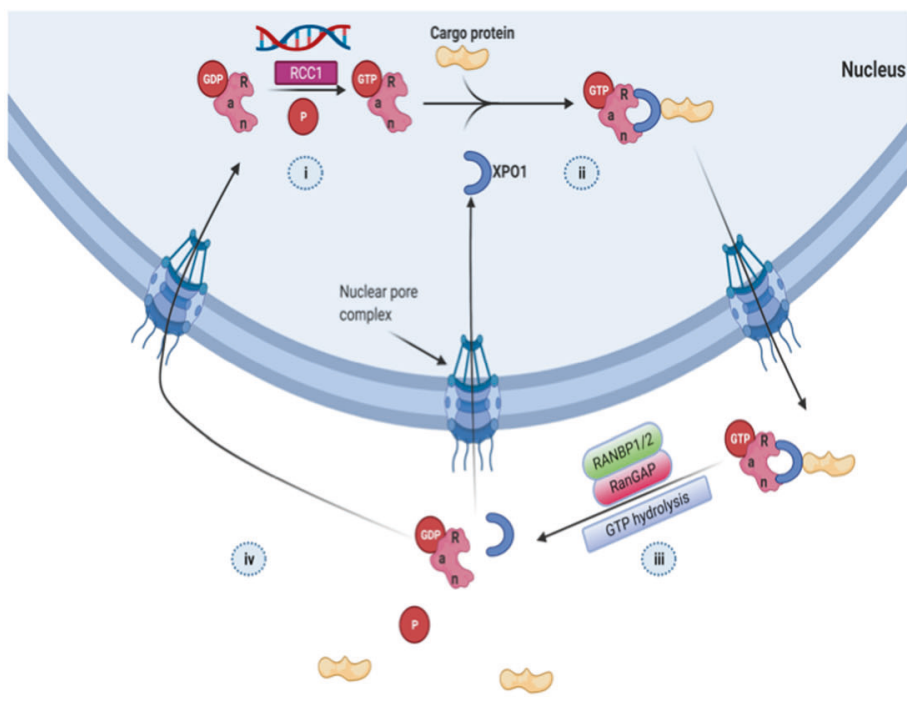

Cytoplasm

A.

NES, nuclear export signal; Chr, chromosome; RCC1, regulator of

chromosome condensation 1; Ran, Ras associate nuclear protein

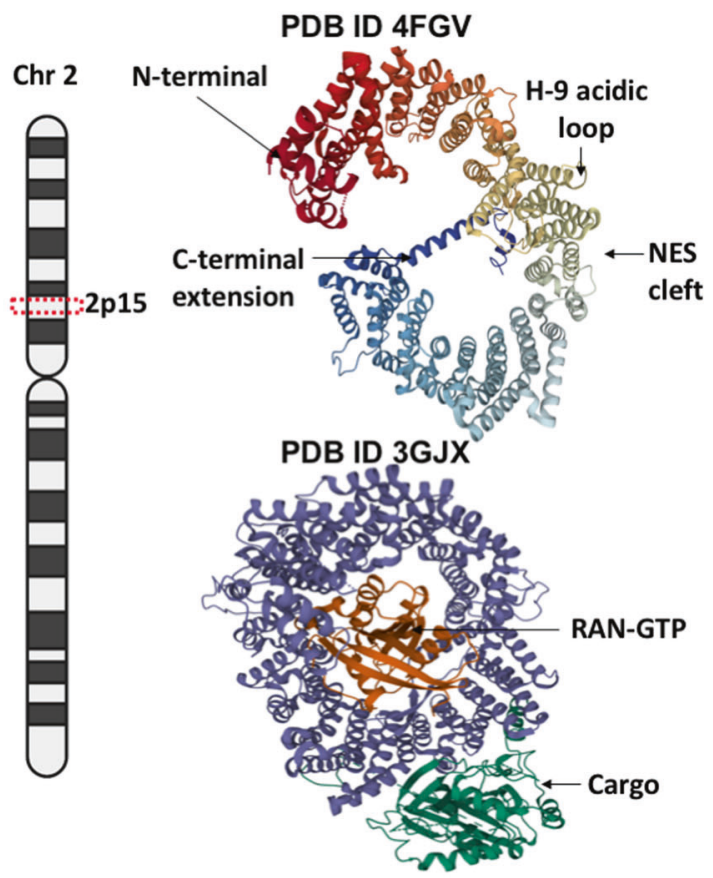

B.

Fig. 1 An illustrative picture of XPO1-dependant nuclear transport. A Nucleo-cytoplasmic shuttling process transports various cargo proteins critical for cellular functions through nuclear pore complexes (NPCs) that facilitate macromolecular exchange. (i), The chromatinbound nucleotide exchange factor, the regulator of chromosome condensation 1 (RCC1) in the nucleus, aids the conversion of RanGDP to RanGTP. (ii), RanGTP binds with cargo protein-loaded XPO1, causing a conformational change to expose the binding site's nuclear export signal (NES). The cargo protein's leucine-rich NES domain interacts with the NES binding site of XPO1. The active complex containing RanGTP, XPO1, and the corresponding cargo protein is docked into the NPC and subsequently shuttled out of the nucleus. (iii), in the cytoplasm, the RanGTP-XPO1-cargo loaded complex is subjected to GTP hydrolysis with RanGAP (GTPase activating protein) along with other protein ligases, including RanBP1/2. First, it releases the RanGTP off the complex and, on hydrolysis, converts RanGTP to RanGDP, eventually maintaining a higher gradient of the latter in the cytoplasm. RanGTP less XPO1-cargo complex aids in releasing the cargo from XPO1. (iv), in the final step of the energy-dependent nucleocytoplasmic shuttling, XPO1 is relocated back to the nucleus. B Demonstrates XPO1 gene locus in chromosome 2, the crystal structure of free XPO1 protein, and the cargo loaded RAN-GTP state [obtained from PROTEIN DATA BANK: 10.2210/pdb4FGV/pdb and $10.2210 / p d b 3 G J X / p d b]$.

amino acid sequences in the target proteins called basic residuerich nuclear localization signal (NLS) and a leucine-rich nuclear export signal (NES) $[8,9]$. Protein Data Bank provides crystal structures of NES-cargos bound XPO1 and ternary complexes of RanGTP/XPO1/cargos [10] (Fig. 1B).

Some of the cargoes exported through XPO1 are tumor suppressor proteins (TSPs) and cell cycle regulatory proteins, including p21, p27, p53, RB1, FOXO1, and Cyclin B1/D1. Although multiple studies have shown that upregulated expression of XPO1 is associated with poor prognosis in solid and liquid cancers [1121], there is little data regarding the mechanism(s) leading to upregulated XPO1 expression. More functional information on XPO1 has been revealed by site-directed mutagenesis in the NES binding groove that can significantly reduce the XPO1 affinity to the cargos $[22,23]$. In contrast, C-helix deletion in XPO1 increases its affinity to its cargos, restricting the cargo release rate [24, 25]. Further the identification of recurrent missense mutations $\left(X P O 1^{\mathrm{E} 571 \mathrm{~K}, \mathrm{D} 724 \text {, and } \mathrm{R749})}\right.$ has exposed more mechanistic clues to the role of XPO1 in different cancers [26]. Particular hotspot mutations showed lineage specificity, especially in chronic lymphocytic leukemia (CLL), Hodgkin lymphoma, and primary mediastinal b-cell lymphoma. XPO1 $1^{\mathrm{E} 571 \mathrm{~K}}$ has been predominantly noted in NHL and Hodgkin lymphoma and less commonly in CLL. XPO1 mutations are postulated to alter the hydrophobic NESbinding groove, which might affect the open-closed equilibrium of the exporter, shape, and affinity of the binding groove to become preferential to certain export cargoes. The tumorigenic role of $X P O 1^{E 571 \mathrm{~K}}$ mutation was demonstrated in a Cre-inducible conditional knock-in mouse model where the mice developed a lethal b-cell malignancy similar to human CLL [27]. XPO1 ${ }^{\mathrm{E} 571}$ has also been identified as a founder lesion in preneoplastic lymphocytes, where it can facilitate the acquisition of further genetic and epigenetic perturbations to transform to a malignant phenotype. Despite different explanations for possible functional impact for this mutation in various cancers, in vitro data on cell lines harboring the mutation did not show differential sensitivity to XPO1 inhibitors [28]. The prevalence of $X P O 1^{\mathrm{E} 571 \mathrm{~K}}$ posttreatment in smaller studies has shown to be a negative prognosticator on survival and hence may serve as a biomarker for response but pending validation from larger studies [29].

More recently, it has become evident that XPO1 function is not just limited to the transport of TSP cargoes but also has a role in drug resistance, retaining master transcription factors essential for cell differentiation, cell survival, and autophagy. The mechanistic aspects of XPO1 inhibition using SINE (Selective Inhibitors of Nuclear Export) compounds can affect various processes that are associated with cancer cell proliferation, survival, adhesion, migration, or metastasis, and many of them are downstream of other known targets. The downstream action suggests that XPO1 inhibition could address the issue of pathway signaling redundancy and/or cross-talk contributing to drug resistance.

The introduction of SINE compounds and discernment of their critical role in nuclear transport has generated numerous studies focusing on the manipulation of carcinogenic pathways, including in AML. Unfortunately, these preclinical findings have not yet translated into success in early phase clinical trials in AML [30]. This is at least in part attributed to the expected off-target effects and resultant interruptions in therapy using first-generation SINE 
compounds rather than pharmacodynamic failure. Given the interest in combining SINEs with other therapies, the paradigm established in the treatment of multiple myeloma-namely using lower and more tolerable doses of SINEs in combination with other agents [31], may be an effective approach in other hematological neoplasms going forward.

\section{Evolution of XPO1 as a target}

The concept of nuclear export inhibition dates back to the 1990s with the antitumor antibiotic leptomycin B (elastocin) [32, 33]. This compound irreversibly blocks Cys528 of XPO1 in the NES domain [32] (Fig. 1B). However, the phase 1 clinical trial with leptomycin B for refractory cancer patients was hampered by toxicities [34] attributed to the irreversible binding nature with the target. Development of other natural XPO1 inhibitors, including but not limited to leptomycin $A$, anguinomycins [35], and ratjadones $A / B /$ C/D [36] produced similarly lackluster results.

Newer drug development strategies, namely ConsensusInduced Fit Docking (cIFD) methodology, established a novel approach to XPO1 inhibition with the development of the SINE class of XPO1 inhibitors [37]. These compounds, KPT-185, KPT-251, KPT-276, KPT-330 (selinexor), KPT-335 (verdinexor), KPT-8602 (eltanexor), and SL-801 (felezonexor), are reversible covalent small molecular inhibitors of XPO1 and hence expected to be less toxic than the previous generation compounds [38-44]. Because of the availability of modern improved XPO1 inhibitors, their logical applications in leukemias with specific mutations, myelodysplastic syndrome/acute myeloid leukemia (MDS/AML), non-Hodgkin's lymphoma ( $\mathrm{NHL})$, and multiple myeloma (MM) may be more rational and involve combinations with old and new drugs.

\section{Role of XPO1 inhibition in driver mutations/pathways enriched in hematological neoplasms}

Inhibition of XPO1 with SINE compounds affects various known genetic drivers in hematological malignancies (Fig. 2). Some of these genetic drivers have currently approved targeted agents, while the rest are in the development pipeline.

TP53 and XPO1. TP53, a frequently mutated or deleted gene in hematological malignancies, is regulated by $M D M 2$, an E3 Ubiquitin ligase [45]. XPO1 transports both p53 and MDM2, and previous preclinical studies have shown synergism in XPO1 and MDM2 inhibitors (selinexor and milademetan) in AML [15]. This effect was associated with upregulation of the TP53 pathway, inhibition of cMyc, and reduction of Ki-67 levels.

NPM1 and XPO1. NPM1 (Nucleophosmin 1) is a frequently mutated gene in AML and confers an overall good prognosis $[46,47]$. The insertion mutation in the highly conserved W288 or W290 residue of the $C$ terminal end in NPM1 causes a frameshift in the read that replaces an NLS (nuclear localization signal) with an NES. The net imbalance in the nuclear retaining signal shuttles out the mutant NPM1 (NPM1c) to the cytoplasm, which co-transports the master transcription factor PU.1 (SPI1) with it. The absence of PU.1 in the nucleus toggles the nuclear transcription collaborators CEBPA and RUNX1 to act as co-repressors instead of activators of

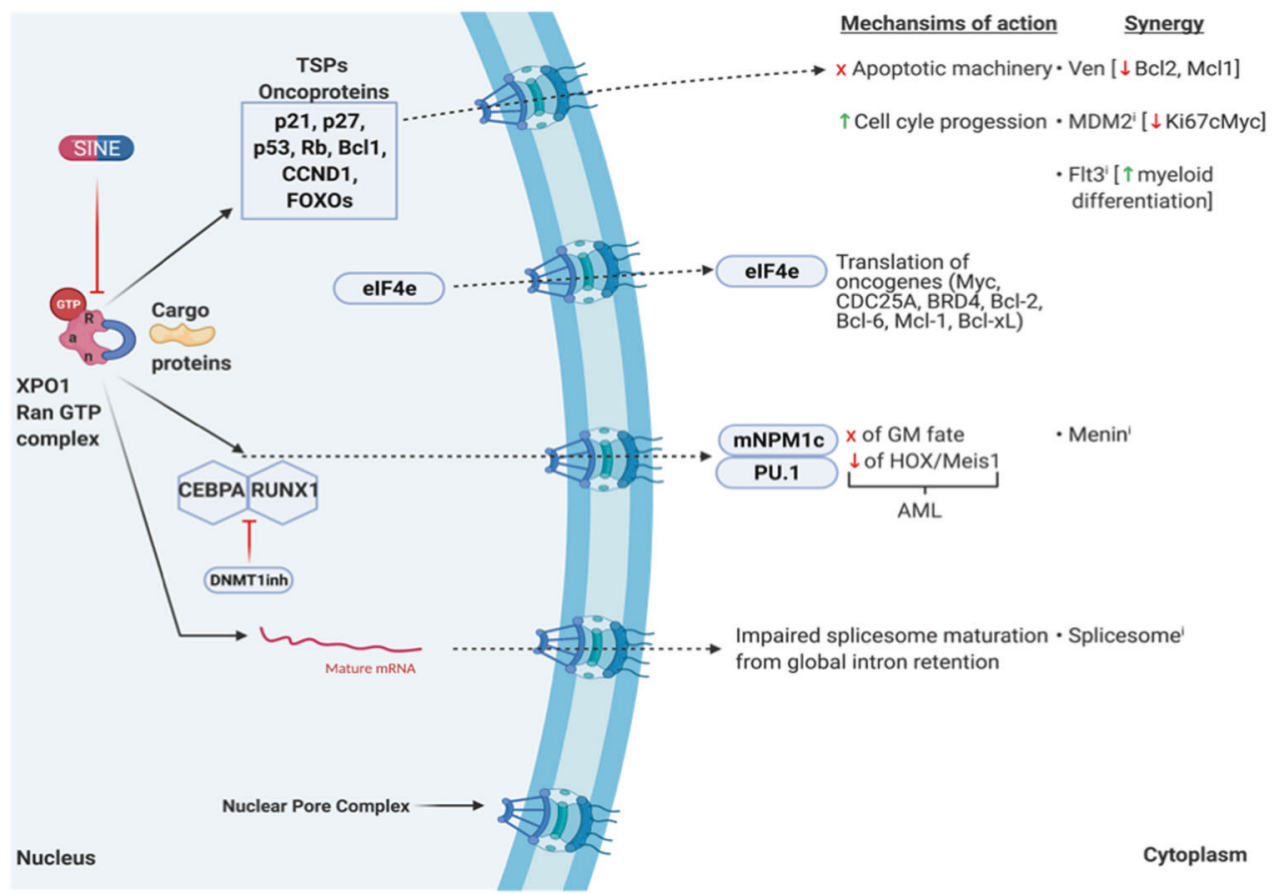

MDM2i, MDM2 inhibitor; Flt3i, Flt3 inhibitor; Menini, menin inhibitor; Spliceosomei, spliceosome inhibitor; GM, granulomonocytic; TSP, tumor suppressor protein; Ven, venetoclax

Fig. 2 Mechanistic pathways interrupted by XPO1 inhibition and possible synergies. XPO1 transports several cellular protein cargoes and RNAs across the nuclear membrane into the cytoplasm. Important cargoes include tumor suppressor proteins like Rb1, p53, APC, and others to apoptosis. Potential synergy with anti-apoptotic inhibitors like Bcl2 (Ven, venetoclax) and MDM2 inhibitors is illustrated. Cell cycle growth regulators shuttled through XPO1 like p21, p27, and cyclin B1 maintain tumorigenesis. FLT3ITD, an oncogene in AML, can be inhibited by combining FLT3 and XPO1 inhibitor. NPM1 (Nucleophosmin) mutation translocate master transcription factor for monocytic differentiation PU.1 along with it to the cytoplasm when mutated. The NPM1c/PU.1 complex export dislocates it from CEBPA/RUNX1 transcription factor essential for granulomonocytic (GM) differentiation. XPO1 inhibition locks NPM1 within the nucleus enabling terminal monocytic differentiation. Upregulated Meis1/Hoxa9 in NPM1 mutant AML is downregulated when NPM1 is retained within the nucleus and can synergize with menin inhibitors. CEBPA/RUNX1 interactome act as co-repressors on differentiation when unbound by NPM1/PU.1 complex and, when inhibited with DNMT1 inhibitors like decitabine, can aid GM terminal differentiation. 
604

approximately 500 downstream genes essential for granulomonocytic differentiation (Fig. 2). XPO1 inhibition retains NPM1/PU.1 within the nucleus and thus activates monocytic fates [48]. In addition, NPM1c-mediated expression of the homeobox genes HOX/Meis1 could explain the maintenance of the immature stemlike leukemic state in NPM1 mutant AML. A phase 1 trial demonstrated safety with selinexor as monotherapy in the R/R (relapsed/ refractory) AML setting (NCT01607892) [49]. Only 1/5 of NPM1 mutated patients in the cohort of 95 total AML patients in the study had a complete response (CR). A definite causal relationship between mutational status and response could not be ascertained. A phase II study [N=42] of selinexor with $7+3$ backbone for R/R AML patients found 3 out of 4 NPM1 mutated patients in their trial with $C R[50,51]$. XPO1 inhibition in NPM1 mutated $A M L$ provides multiple targetable strategies either as monotherapy or in combination with, e.g., menin/KMT2A inhibitors [52], as it was shown to decrease expression of HOX/Meis1 as well.

$B C L 2, M C L 1$, and XPO1. While BCL2 is often overexpressed in a range of hematological neoplasms, the anti-apoptotic dependence can be heterogeneous, especially in AML. Other antiapoptotic proteins like MCL-1 and $\mathrm{BCL}-\mathrm{xL}$ are often enriched in a mixed clone, and hence targeting BCL2 alone may be insufficient to eliminate the leukemic process. Because XPO1 regulates both $\mathrm{BCL}-2$ and $\mathrm{MCL}-1$ transport from the nucleus to the cytoplasm for translation [with a chaperon protein Leucine-rich PPR-motifcontaining protein (LRPPRC)], SINE compounds/BCL2 inhibitor combination was shown to enhance cell death in in vitro experiments and patient-derived xenograft models in AML. SINE compounds perhaps prevent elF4E (translation initiation factor) from augmenting BCL2 and MCL1 mRNA translation [53,54]. The adjunct studies also support the ex vivo sensitivity of primary venetoclax refractory patient samples to the combination of SINEVenetoclax. This combination was also tested to be synergistic in a different study with primary AML and DLBCL cells, and its action was mechanistically shown to be independent of P53 status [55]. It can potentially be a clinically significant finding, especially in $17 p$ del CLL patients where anti-apoptotic factor MCL1 is degraded by other mechanisms.

FLT3 and XPO1. Generally, the FLT3 gene mutation in AML is considered a poor prognosticator though the allelic frequency could partly impact this negative correlation's strength [56, 57]. Dual targeting of XPO1 and FLT3 increased pro-apoptotic signal by retaining TSPs in the nucleus [58]. The combination was synergistic in vitro and in in vivo human xenograft FLT3 mutated mouse models. Myeloid differentiation of the FLT-ITD clone was enhanced by co-targeting XPO1 and FLT3 instead of targeting either alone. An early-phase study with R/R FLT3 mutated AML patients [58] [50\% exposed to prior FLT3 inhibitors] showed a sustained CRi/CRp (complete remission with incomplete hematological recovery/complete remission with incomplete platelet recovery) in $29 \%$ (4/14), and two additional patients (14\%) showed more than $50 \%$ blast reduction. Moreover, the responding patients were also MRD (measurable residual disease) negative for FLT3-ITD by RT-qPCR.

SF3B1 and XPO1. A recent post-hoc analysis from a phase 2 study in MDS [59] and oligoblastic AML (20-30\% blasts) patients refractory to hypomethylating agents (HMAs) demonstrated patients with the canonical splicing factor mutation in SF3B1 responding significantly better to selinexor. While SF3B1 is mostly a good prognosticator in MDS, in this study, the SF3B1 patients had high-risk disease by IPSSR. Inhibition of XPO1-mediated RNA transfer required for spliceosome machinery's maturation may produce synthetic lethality in SF3B1 mutant disease, and this selective sensitivity of SF3B1 to XPO1 inhibition merits further research.
Epigenetic perturbations and XPO1 inhibition. Hypomethylating agents affecting epigenetic perturbations in myeloid neoplasms have been combined with other novel agents. Recent preclinical studies, both in vitro and in vivo, showed decitabine priming to enhance the antileukemic effects of selinexor [60]. The synergism was more evident at lower doses of selinexor. It hence could avoid the potential untoward toxicities of higher doses of selinexor used in other studies as a single agent.

\section{Overcoming drug resistance with XPO1 inhibition}

Imatinib/dasatinib (Fig. 3). Protein mislocalization is one of the critical factors recognized in oncological drug resistance. Despite successes in treating CML with tyrosine kinase inhibitors (TKI), some patients still develop TKI resistance. Studies using TKI with leptomycin B (XPO1 inhibitor) demonstrated BCR-ABL trapping within the nucleus, causing irreversible and complete destruction of the BCR-ABL clone [61]. Ex vivo studies using human CML samples also corroborated those findings [62]. Targeting nuclear export can eradicate CML clones in scenarios, especially where there are TKI resistant mutations. The implications are broader and perhaps be applicable in all ph+ leukemias and CML blast crisis.

Bortezomib/carfilzomib. Acquired resistance to proteasome inhibitors (PI) is common in MM. A proteomics-based approach [63] revealed and validated one hundred and twelve regulatory proteins differentially expressed with bortezomib resistance in MM, and many of them interacted with XPO1 [63] (CSE1, DYNLL1, HSPA14, NUP88, NUP50, RAD21, RCC2, RANBP2, SMC1A, and TPR). XPO1 knockdown in myeloma cell lines reestablished sensitivity to proteasome inhibitor. Thus, XPO1 inhibition could help overcome drug resistance in $\mathrm{MM}$. Preclinical studies tested PI-resistant myeloma cell lines and patient-derived xenograft models treated with selinexor/bortezomib or carfilzomib [64] resensitized resistant cells by diminishing NFKB transcriptional activity.

Anthracyclines and cytarabine. AML can develop resistance to Topo II inhibitors (anthracyclines and etoposide) when Topo Ila is mislocalized to the cytoplasm. This displacement is XPO1 mediated, and SINE compounds have been shown to retain Topo Ila back in nucleus reestablishing sensitivity to the Topo II inhibitors [65]. In a head and neck cancer model, XPO1 inhibition was shown to prevent cytoplasmic mislocalization of the transcriptional repressor E2F7 from its nuclear transcriptional activator E2F1 counterpart (for drug-resistant genes) and thus overcome anthracycline drug resistance [66].

Ibrutinib. Selinexor has single-agent activity in CLL cells and, when combined with ibrutinib, cause synergistic cytotoxicity in primary CLL cells [67]. Selinexor is also effective in vitro in CLL cells harboring a resistant BTK C481S mutation and in vivo in the ibrutinib-refractory mice model. Mechanistically, ibrutinib resistant cells decrease FOXO3a levels in the nucleus, and selinexor could overcome ibrutinib resistance by retaining $\mathrm{FOXO} 3$ a within the nucleus [68]. It is noted that failure to inhibit NFKB transcriptional signature is associated with ibrutinib resistance in $M C L$ cell lines [69]. Selinexor retains $1 K B, P 65$, and P50 within the nucleus and in the bound state; P65 and P50 are inactive in DNA binding. Hence, targeting downstream of $B C R$ signaling on NFKB with selinexor could negate the acquired upstream resistance mutations.

\section{Clinical studies in MDS/AML with SINE compounds-an overview}

Table 1 provides a list of MDS and/or AML trials involving XPO1 inhibitor therapy. Below, we provide additional details regarding some of these studies.

Selinexor monotherapy is safe and, in some cases, efficacious in patients with advanced hematological malignancies based on a phase 1 study [49]. After a robust anti-leukemic activity in AML 


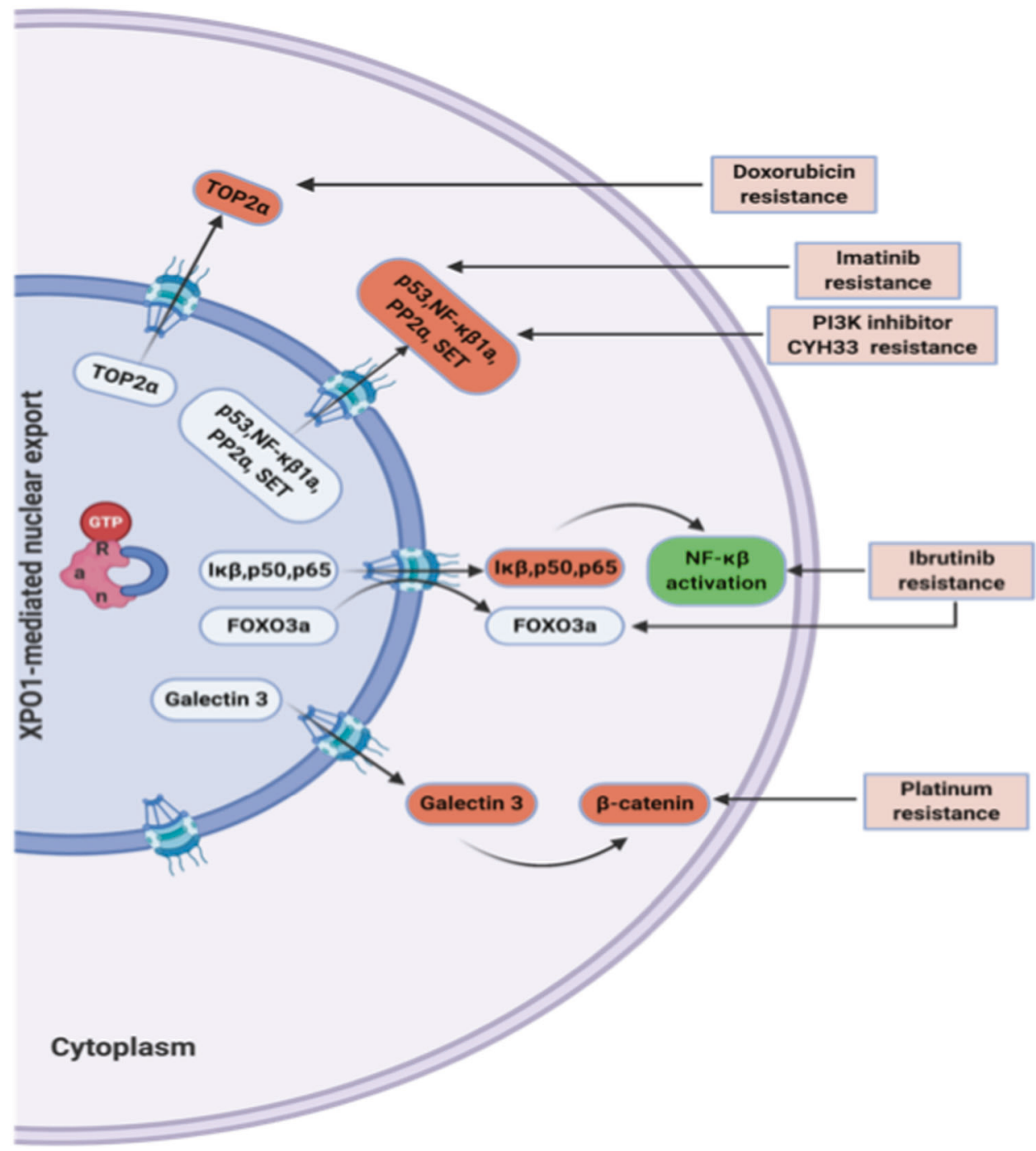

Fig. 3 Mechanisms of XPO1 mediated emergent drug resistance pathways. Increased XPO1 expression mediates nucleocytoplasmic displacement and inactivation of tumor suppressor proteins, leading to tumorigenesis as well as emergent drug resistance. Cytoplasmic dislocation of P53 is implicated in imatinib's acquired drug resistance and PI3K inhibitor CYH33. Mislocalized topoisomerase $2 \alpha(\mathrm{TOP} 2 \mathrm{~A}$ ) to the cytoplasm is linked to doxorubicin resistance. Ibrutinib resistance is associated with XPO1 mediated nuclear export of inhibitors of NF- $\kappa B$ (IКB), P50, and P65, leading to activation of NF-KB signaling pathway. The nuclear export of FOXO3A is illustrated in acquired ibrutinib resistance, which XPO1 inhibitors can overcome. Platinum resistance is linked to $\beta$-catenin, which is regulated by the XPO1 mediated cytoplasmic displacement of Galectin 3.

preclinical models, 95 patients with R/R AML not candidates for chemotherapy were enrolled in this trial [NCT01607892]. In a heavily pretreated population ( $>3$ lines of prior therapy), 7 out of 81 evaluable patients (14\%) responded [five complete responses (CR) and two complete responses with incomplete hematological recovery $(\mathrm{CRi})]$. In responding patients, the median progression-free survival (PFS) and overall survival (OS) were 5.1 and 9.7 months, respectively. Stable disease (SD, $\leq 50 \%$ increase in BM blasts from baseline) was noted in $65 \%$ of patients. While no cytogenetic or molecular features correlated with response, patients with low blast count or hypoproliferative AML responded better. A separate single-arm phase II study examining selinexor as therapy for patients with HMA refractory myelodysplastic syndrome, or oligoblastic acute myeloid leukemia [59] showed selinexor to have promising activity. 6 of 23 evaluable patients (26\%) attained a marrow $C R$, and 12 patients (52\%) had SD. Interestingly, the post-hoc analysis revealed patients with disease harboring SF3B1 mutations had a higher likelihood of responding [59].
After preclinical work showed selinexor had robust activity in AML post decitabine priming [60], a phase I dose-escalation study assessing selinexor in combination with HMAs in older (age $\geq 60$ ) relapsed/refractory $(R / R)$ and newly diagnosed (N/D) AML patients $[N=25$ ] [70] was done. More than half were heavily pretreated ( $\geq 3$ lines of prior therapy). The ORR was $40 \%$ (10/25 patients). Five of the responders achieved a CR, and another three had attained a CRi. Selinexor was better tolerated at $60 \mathrm{mg}$ (flat dose) given twice a week for 2 weeks after decitabine treatment. Selinexor was also combined with other DNA-damaging conventional chemotherapies in several small early phase studies that included N/D poorrisk $A M L$ or $R / R$ disease [50, 71-74]. A single-arm phase 1 study of selinexor with the traditional $7+3$ regimen [cytarabine and daunorubicin] for N/D poor-risk AML patients [74] showed a CR/ CRi of $53 \%$ (10/19: 8CR, 2CRi). More than a third of patients were alive at the median follow-up of 28.9 months. The study established the safety of adding selinexor to the conventional $7+3$ backbone, with a response rate at the upper end of the historically reported range for poor-risk N/D AML (20-50\%) [75]. 


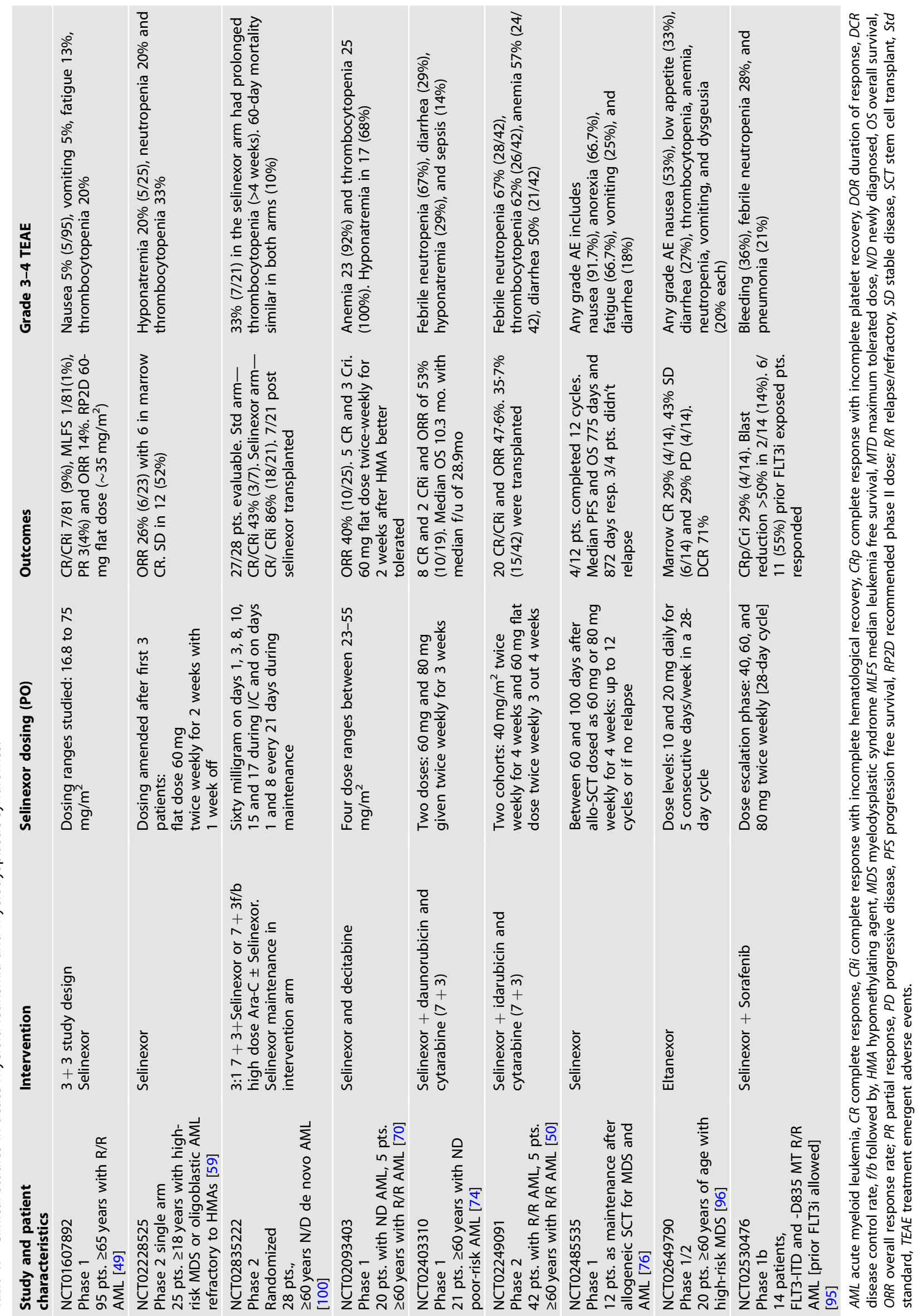



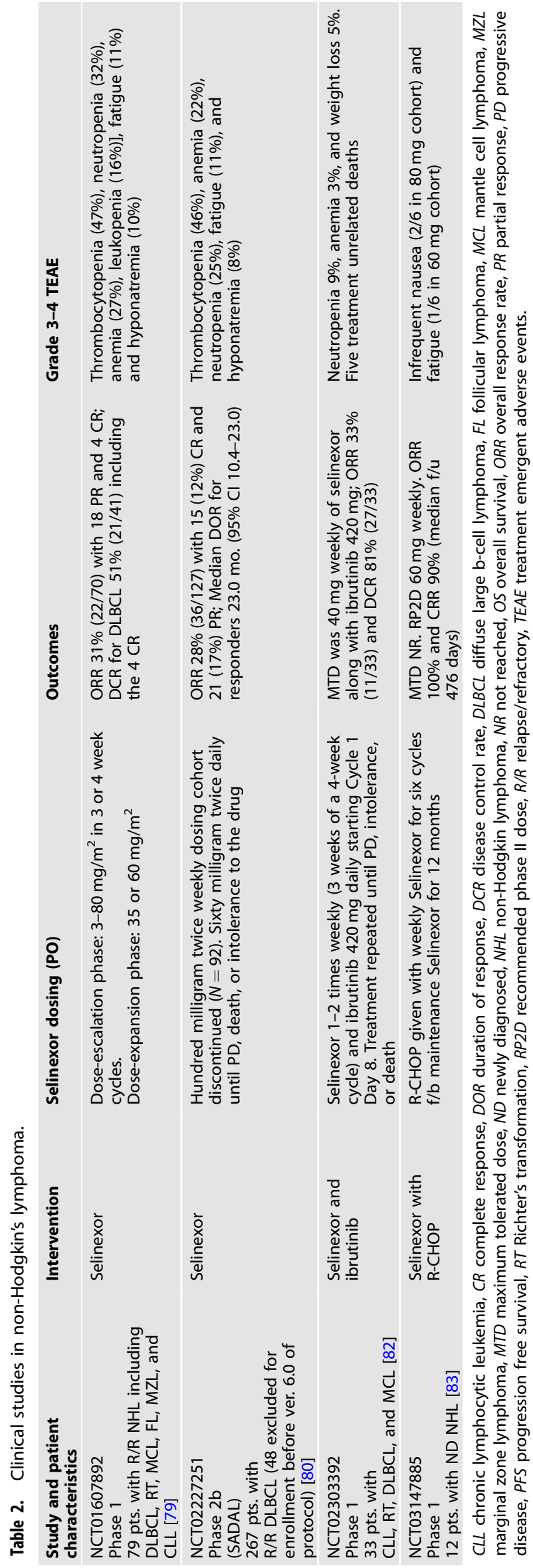

Although some patients with AML and MDS are cured with allogeneic stem cell transplant, the majority of these high-risk patients ultimately relapse. Maintenance selinexor post hematopoietic stem cell transplant for MDS and AML patients delayed relapse in a small study [76]. Three out of the four patients who completed all the 12 cycles had not relapsed at the time of the published report.

In conclusion, selinexor has demonstrated potential as monotherapy and in combination with other novel agents and chemotherapy in MDS/AML. Improved response rates amongst patients with low blast count disease argue its applicability in high-risk MDS patients rather than in high blast count AML, where the biology may differ. Dose and/or schedule modification to improve overall tolerance of selinexor-based therapy is perhaps a clinically meaningful strategy for older and less fit AML/MDS patients with limited treatment options. Also, further clinical work assessing the activity of XPO1 inhibitors in patients with specific molecular features (e.g., SF3B1) and/or clinical parameters is needed to determine whether any particular subgroup of patients stands to benefit more from these drugs. Selinexor as a maintenance strategy in the post-stem cell transplant or other therapies seems reasonable and needs further exploration.

\section{Clinical studies in non-Hodgkin's lymphoma (Table 2)}

Despite the availability of cellular therapies for patients with $R / R$ $\mathrm{NHL}$, overall such patients have a poor prognosis $[77,78]$. Moreover, only a fraction of patients qualify for such intensive treatment. Hence, there is an unmet need in developing novel therapeutics for this patient population.

Selinexor as monotherapy was tested in a phase 1 trial [79] with seventy-nine non-Hodgkin's lymphoma (NHL) patients [chronic lymphocytic leukemia (CLL), diffuse large B-cell lymphoma (DLBCL), follicular lymphoma (FL), mantle cell lymphoma (MCL), and Richter's transformation (RT)]. Among the 70 evaluable patients, 22 (31\%) had an objective response, including 18 partial responses (PR) and $4 \mathrm{CR}$. All four CRs were seen in the DLBCL patients [10\% (4/41)]. Including SD, the DLBCL cohort had a disease control rate (DCR) of 51\% [21/41]. Six patients who showed some response were either double or triple hit lymphomas. There was $1 \mathrm{CR}$ and 2 PR in this subgroup of aggressive histology. The FDA recently approved selinexor for $R / R$ DLBCL patients [ $\geq 2$ lines of prior treatment] after a subsequent multinational open-label phase $2 \mathrm{~b}$ study, SADAL $[80,81]$, showed an ORR of $28 \%(36 / 127$ evaluable patients), including $15 \mathrm{CR}(12 \%), 21 \mathrm{PR}(17 \%)$, and 11 SD (9\%). More patients in the germinal center B-cell (GCB) cohort responded [ORR 34\% (20/59)] than in the non-GCB cohort [21\% (13/63)]. In a phase 1 trial of selinexor plus ibrutinib [82] involving 33 patients with R/R CLL/NHL [16 CLL, 8 Richter's transformation, 6 $\mathrm{DLBCL}$, and $3 \mathrm{MCL}$, disease control was achieved in $81 \%$. Among them, $33 \%$ had CR or PR, and the remaining maintained SD. Prior ibrutinib exposure was best associated with SD, whereas ibrutinib not-exposed patients showed CR or PR. Of note, the two CLL pts with known BTK mutation responded to the combination treatment. Also, one of the six RT patients who responded had a CR. After a median follow up of 5.3 months (1.2-22.5 months), median PFS/OS for CLL and NHL patients were 8.9 (95\% Cl: 4.6-NR)/NR (95\% Cl: 15.4-NR) and 2.7 (95\% Cl: 0.7-NR)/5.4 (95\% Cl: 2.6-NR) mo., respectively.

The clinical feasibility of combining R-CHOP with selinexor in the frontline management of newly diagnosed $\mathrm{NHL}$ was shown in a phase $1 \mathrm{~b}$ study with durable efficacy and a tolerable safety profile [83]. In that study $(n=12)$ with ten evaluable patients for a response, ORR and CRR were reported as $100 \%$ and $90 \%$, respectively, after a median follow-up of 476 days. The RP2D of selinexor was $60 \mathrm{mg}$ weekly. A separate phase lb trial studying the combination of venetoclax and selinexor [NCT03955783] is currently recruiting for a total enrollment of 78 patients with 
608

high-risk $\mathrm{R} / \mathrm{R}$ hematologic malignancies [AML and $\mathrm{DLBCL}]$ [Supplemental Table 1] is expected to report results by 2023.

In summary, selinexor is promising both as monotherapy and in combination therapy effective in different b-cell lymphomas. The robust RR in newly diagnosed NHL when selinexor is given in combination with upfront standard of care treatment supports the rationale for further testing, which is ongoing. The preferential response seen in aggressive $\mathrm{R} / \mathrm{R} \mathrm{NHL}$ makes it more attractive to add selinexor in different combination regimens.

\section{Clinical studies in multiple myeloma (Table 3 )}

Novel agents used in treating $\mathrm{MM}$ have changed the dismal outlook of an aggressive disease to an illness that can be managed effectively. Despite these advances, the disease is still not curable. Hence, there is a salient need to probe for targeting unique pathways with novel agents.

The single-agent activity of selinexor in heavily pretreated MM patients [84] was suboptimal, with $21 \%$ of patients achieving a minor hematologic response or better but an objective response rate (ORR, defined as a partial response or better) of only $4 \%$. However, the addition of corticosteroids substantially increased the ORR to $50 \%$. The ORR for single-agent glucocorticoids in a heavily pretreated population is historically in the range of $6-10 \%$, strongly suggesting the combination of selinexor and dexamethasone synergize [85]. Preclinical evidence supported selinexor in combination with steroids to potentiate apoptosis in myeloma cells, possibly from repressed mTORC1 signaling [86, 87].

The FDA approved selinexor for R/R MM after the subsequent phase 2b STORM trial (NCT02336815, part I, Selinexor Treatment of Refractory Myeloma) [88] demonstrated an ORR of $21 \%$ and a clinical benefit rate $(C B R=V G P R$, very good partial response + $\mathrm{PR}+\mathrm{MR}$, minimal response) of $33 \%$. Of note, $40 \%$ (31/79) of the study population were penta-refractory, including resistance to an anti-CD38 monoclonal antibody. High risk cytogenetic group $[t(4 ; 14), t(14 ; 16)$ and del $17 p]$ had an ORR of $35 \%$ and a CBR of $53 \%$. The median PFS and OS were 2.3 and 9.3 months, respectively. The second part of the STORM trial [89] was a confirmatory study that enrolled a more homogenous cohort of $\mathrm{R} / \mathrm{R} \mathrm{MM}$ patients (median number of prior treatments $=7$ ). More importantly, these patients were penta-exposed but triple class refractory (at least one immunomodulatory agent, one proteasome agent, and anti-CD 38 antibodies). The ORR was 26\% (32/122; 2 stringent complete responses, 6 VGPR, and 24 PR), and the CBR was $39 \%(48 / 122)$. The two patients with a history of CAR-T cell therapy also had a PR. The median duration of response, PFS, and OS were 4.4 (95\% Cl 3.7-10.8), $3.7(95 \% \mathrm{Cl} 3.0-5.3)$, and $8.6(95 \% \mathrm{Cl}$ $6.2-11.3)$ months, respectively. A post hoc analysis [90] showed the combination to be effective for plasmacytomas. Approximately less than half of the plasmacytoma patients $(44 \%, 7 / 16)$ in the study with follow-up assessments showed complete resolution or decreased extramedullary disease size or metabolic activity. Based on this data, the FDA approval specifies that MM patients treated with selinexor must be refractory to at least two Pls, two immunomodulatory agents, and an anti-CD 38 monoclonal antibody are eligible to receive selinexor plus dexamethasone.

A phase $1 \mathrm{~b} / \mathrm{ll}$ trial [STOMP] established the safety of using the triplet combo (bortezomib, dexamethasone, and selinexor) to treat $\mathrm{R} / \mathrm{R}$ MM [N=42] [91]. In this trial, the ORR was $63 \%$ and approximately half of the patients previously documented to be refractory to proteasome inhibitor-based therapy responded. The median PFS was 9.0 months. Of note, there was a lower incidence of neuropathy, an important dose-limiting toxicity of bortezomib. In the phase 3 (BOSTON) [31] open-label study, 402 MM patients who had received 1-3 lines of prior therapy were randomized to bortezomib and dexamethasone with $(N=207)$ or without selinexor $(N=195)$. The triplet arm with selinexor had a superior median PFS of 13.93 months ( $95 \%$ Cl $11.73-$ not evaluable) vs. the doublet with 9.46 months [(8.11-10.78); HR 0.70] after a median follow-up of 13.2 months (IQR 6.2-19.8). The triplet arm had a significantly superior ORR as well compared to the doublet arm [76.4\% (95\% Cl 69.8-82.2) vs. 62.3\% (55.3-68.9); odds ratio (OR) 1.96 ] and reported less frequent $\geq$ Grade 2 peripheral neuropathy [41 (21\%) vs. 70 (34\%); odds ratio 0.50 (95\% Cl 0.32-0.79), $p=$ $0.0013]$. Though nuclear export inhibitors may reverse inflammatory demyelination [92], in this case, the less frequent bortezomib dosing (once weekly) in the triplet arm seemed a likely reason for the lower incidence of neuropathy. The favorable efficacy, even in bortezomib refractory patients, led the FDA to approve the combination of selinexor, bortezomib, and dexamethasone to treat adult MM patients in the first relapse. The ORR (38\%)and CBR (67\%) were comparable when selinexor was combined with a different proteasome inhibitor carfilzomib in a phase 1 study [93]. When given in combination with daratumumab and dexamethasone in a phase $1 / 2 b$ study [94] with heavily treated $R / R M M$ patients $[N=34$ with more than $2 / 3$ rds of the patients $(71 \%)$ having had autologous stem cell transplant], the ORR and CBR were $69 \%$ and $81 \%$, respectively (compared to 73 and $87 \%$ in the daratumumab naïve arm).

Overall, although selinexor has minimal single-agent activity in myeloma but regimens using the drug in combination with steroids and other novel agents result in far more efficacious clinical utility both in R/R and newly diagnosed MM. It also enables dose reductions of other agents used in the treatment of $M M$, ultimately improving the tolerability of the backbone regimen. Hence, future work will focus on using selinexor as a synergistic partner drug to other established and experimental anti-myeloma agents.

\section{Treatment-emergent adverse events and newer generation SINE compounds (Tables 1-3)}

Hematological toxicities are common with selinexor and often require closer monitoring, especially in heavily pretreated patients with baseline cytopenias [31, 49, 51, 59, 76, 77, 80, 95]. This is likely from the poor bone marrow reserve. The most common nonhematological toxicities include fatigue, hyponatremia, nausea, vomiting, and diarrhea which are a class effect of the medication. Importantly, eltanexor (KPT 8602), a second-generation SINE compound with a similar pharmacokinetic profile as selinexor, has an improved side effect profile compared to selinexor, likely from far lower blood-brain-barrier penetration. Further, preclinically, eltanexor is efficacious against leukemia-initiating cells and AML blasts in vivo [39]. A phase $1 / 2$ study [96] found single-agent eltanexor to be effective in elderly HMA-refractory HR-MDS (14 evaluable patients), where ten had meaningful responses with a disease control rate of $71 \%$ [four marrow $(\mathrm{m})$ CR (29\%) and six SD $(43 \%)]$, and the remaining progressed (29\%). Eltanexor was evaluated for safety and tolerability in a separate phase 1 study $(N=39)$ involving $\mathrm{R} / \mathrm{R} M M$ patients (median prior therapies $=7$ ). The ORR was modest [21\% (7/34)] among the 34 evaluable heavily pretreated population, and the CBR was $47 \%$ (16/34). The most frequent grade 3-4 TEAEs were hematological; thrombocytopenia $56 \%$ (22/39), neutropenia 26\% (10/39), anemia 13\% (5/39), and hyponatremia $8 \%(3 / 39)$. The $\mathrm{Gl}$ and other constitutional side effects were minimal and felt to be less problematic than that seen in other trials in which selinexor was the SINE compound used.

More recent studies in various blood cancers have demonstrated a strategy to mitigate these adverse effects by using selinexor in combination with salicylates [97]. The combination was shown to be not toxic for normal cells. Much of the class toxicity is dose-dependent. Therefore, if novel combinations allow using lower doses of selinexor as in some MDS and lymphoma trials, it could help extract the maximum target efficiency of the drug class, alleviating the emergent side effects. Perhaps, one could also hypothesize that short interrupted use of SINE compounds to synergize with other novel agents to mitigate 


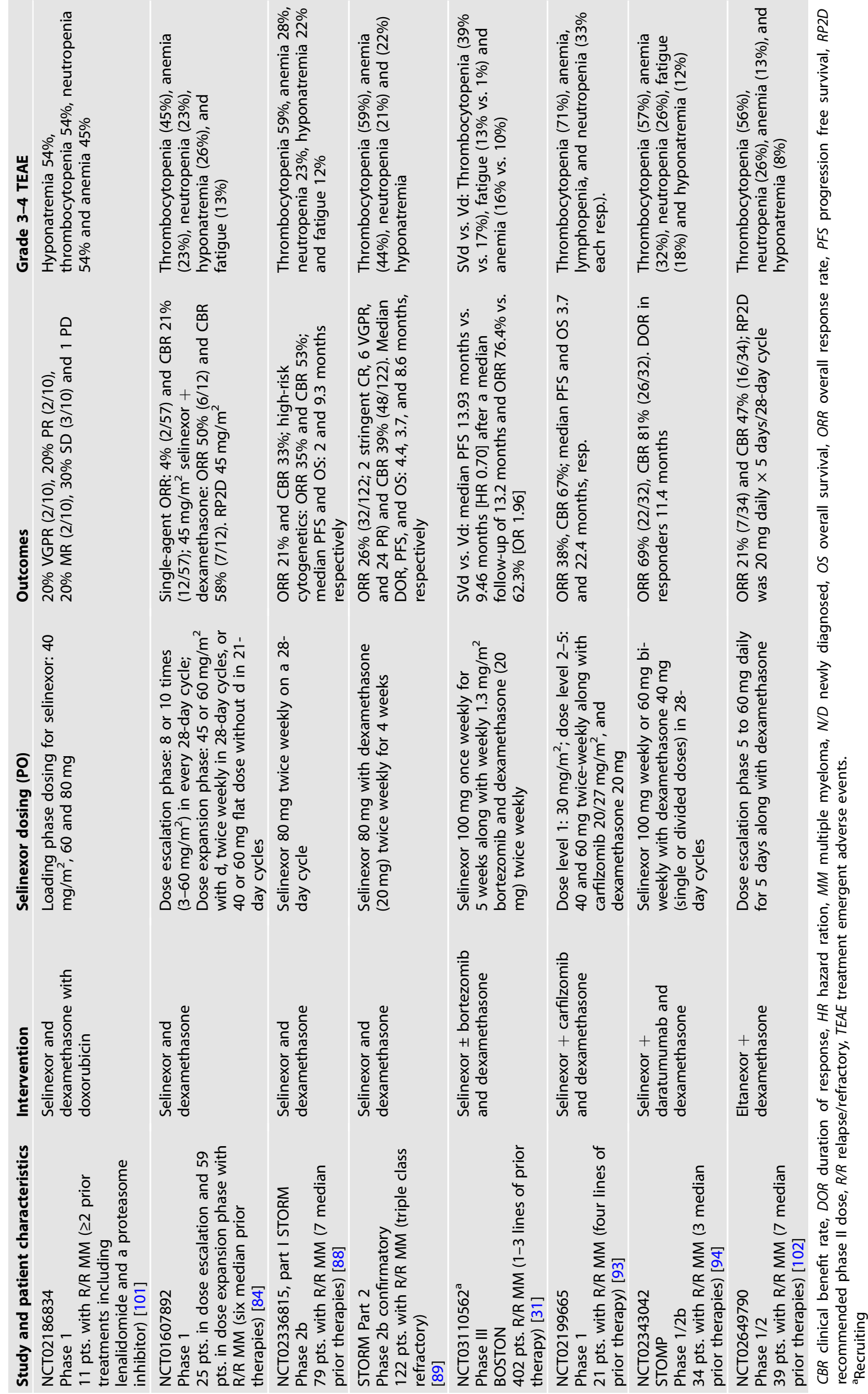


the class's treatment-emergent side effects could be an approach to test.

\section{Novel synergies in the horizon and conclusion (Fig. 2)}

XPO1 inhibition has evolved as a novel target in cancer therapeutics with potential utility across different cancer types. The ability to cross-talk with different interactomes makes it an ideal synergy partner with other targeted therapeutics. Many of these mechanisms of actions of SINE compounds are downstream of activated pathways in cancer and hence can theoretically work in additional upstream acquired target drug resistance. Several preclinical studies have demonstrated this role in a wide variety of solid and hematological neoplasms, including AML/MDS. Combining MDM2 inhibitors and selinexor has been tested and possibly a strategy that can effectively mitigate TP53 mutations in different malignancies. SINE compounds are active in NPM1 mutated AML, ultimately altering the downstream HOX/MEIS program that maintains the leukemogenesis and could be potentially combined with other targeted agents like menin inhibitors. SINE compounds retain pro-apoptotic factors in the nucleus, making it ideal to be combined with $\mathrm{Bcl} 2$ inhibitors, which may also prevent resistance. Spliceosome inhibitors, though, looked promising in preclinical studies [98] showed an only mediocre response in the clinical trial [99]. Thus, the SINE compound could be combined with spliceosome inhibitors for its role in global intron retention, an action common to both classes of drugs.

However, striking a balance between maximizing the anticancer activity of SINE compounds while minimizing toxicity remains a challenge. Second-generation SINE compounds appear to have an improved therapeutic index compared to earlier agents. Still, even with first-generation compounds, there have been some successes in the clinic already, with the FDA recently approving selinexor-based therapy in the second-line setting for relapsed $M M$ patients, as well as in refractory DLBCL as a thirdline agent.

While mechanistically, XPO1 inhibition is a unique strategy, widespread clinical applicability has been confronted by treatment-emergent adverse events exclusive for the drug class. Though its role in multiple cancer hallmarks is considered a strength, it could be a challenge because it inhibits many essential nucleo-cytoplasmic shuttling processes. Finally, further investigations into prognostic biomarkers are also needed to identify patients with tumors that will be selectively sensitive to XPO1 inhibition. Also, patient and clinician acceptance of TEAEs would likely be higher if there was a significantly enhanced likelihood of clinical response.

\section{REFERENCES}

1. Stone RM, Mandrekar SJ, Sanford BL, Laumann K, Geyer S, Bloomfield CD, et al. Midostaurin plus chemotherapy for acute myeloid leukemia with a FLT3 mutation. N Engl J Med. 2017;377:454-64.

2. Ganzel C, Sun Z, Cripe LD, Fernandez HF, Douer D, Rowe JM, et al. Very poor long-term survival in past and more recent studies for relapsed $A M L$ patients: the ECOG-ACRIN experience. Am J Hematol. 2018;93:1074-81.

3. Görlich D, Mattaj IW. Nucleocytoplasmic transport. Science. 1996;271:1513-9.

4. Ohno M, Fornerod M, Mattaj IW. Nucleocytoplasmic transport: the last 200 nanometers. Cell. 1998;92:327-36.

5. Hinshaw JE, Carragher BO, Milligan RA. Architecture and design of the nuclear pore complex. Cell. 1992;69:1133-41.

6. Fukuda M, Asano S, Nakamura T, Adachi M, Yoshida M, Yanagida M, et al. CRM1 is responsible for intracellular transport mediated by the nuclear export signal. Nature. 1997;390:308-11.

7. Fornerod M, Ohno M, Yoshida M, Mattaj IW. CRM1 is an export receptor for leucine-rich nuclear export signals. Cell. 1997;90:1051-60.

8. Hodel MR, Corbett AH, Hodel AE. Dissection of a nuclear localization signal. J Biol Chem. 2001;276:1317-25.

9. Wen W, Meinkotht JL, Tsien RY, Taylor SS. Identification of a signal for rapid export of proteins from the nucleus. Cell. 1995;82:463-73.
10. Berman HM, Westbrook J, Feng Z, Gilliland G, Bhat TN, Weissig H, et al. The Protein Data Bank. Nucleic Acids Res. 2000;28:235-42. https://www.rcsb.org/.

11. Cosson A, Chapiro E, Bougacha N, Lambert J, Herbi L, Cung H, et al. Gain in the short arm of chromosome $2(2 \mathrm{p}+)$ induces gene overexpression and drug resistance in chronic lymphocytic leukemia: analysis of the central role of XPO1. Leukemia. 2017;31:1625-9.

12. Liu X, Chong Y, Tu Y, Liu N, Yue C, Qi Z, et al. CRM1/XPO1 is associated with clinical outcome in glioma and represents a therapeutic target by perturbing multiple core pathways. J Hematol Oncol. 2016;9:108.

13. Noske A, Weichert W, Niesporek S, Röske A, Buckendahl AC, Koch I, et al. Expression of the nuclear export protein chromosomal region maintenance/ exportin $1 / \mathrm{Xpo} 1$ is a prognostic factor in human ovarian cancer. Cancer. 2008; 112:1733-43.

14. Azmi AS, Uddin MH, Mohammad RM. The nuclear export protein XPO1-from biology to targeted therapy. Nat. Rev. Clin. Oncol. 2020;18:1-18.

15. Kojima K, Kornblau SM, Ruvolo V, Dilip A, Duvvuri S, Davis RE, et al. Prognostic impact and targeting of CRM1 in acute myeloid leukemia. Blood. 2013; 121:4166-74.

16. Luo B, Huang L, Gu Y, Li C, Lu H, Chen G, et al. Expression of exportin-1 in diffuse large B-cell lymphoma: immunohistochemistry and TCGA analyses. Int J Clin Exp Pathol. 2018;11:5547.

17. Tai $Y$, Landesman $Y$, Acharya $C$, Calle $Y$, Zhong $M$, Cea $M$, et al. CRM1 inhibition induces tumor cell cytotoxicity and impairs osteoclastogenesis in multiple myeloma: molecular mechanisms and therapeutic implications. Leukemia. 2014;28:155-65.

18. Lapalombella R, Sun $Q$, Williams K, Tangeman L, Jha S, Zhong $Y$, et al. Selective inhibitors of nuclear export show that CRM1/XPO1 is a target in chronic lymphocytic leukemia. Bood. 2012;120:4621-34.

19. Zhang K, Wang M, Tamayo AT, Shacham S, Kauffman M, Lee J, et al. Novel selective inhibitors of nuclear export CRM1 antagonists for therapy in mantle cell lymphoma. Exp Hematol. 2013;41:67-78.

20. Azmi AS, Li Y, Muqbil I, Aboukameel A, Senapedis W, Baloglu E, et al. Exportin 1 (XPO1) inhibition leads to restoration of tumor suppressor miR-145 and consequent suppression of pancreatic cancer cell proliferation and migration. Oncotarget. 2017;8:82144.

21. Sexton R, Mahdi Z, Chaudhury R, Beydoun R, Aboukameel A, Khan HY, et al. Targeting nuclear exporter protein XPO1/CRM1 in gastric cancer. Int J Mol Sci. 2019;20:4826.

22. Güttler T, Madl T, Neumann P, Deichsel D, Corsini L, Monecke T, et al. NES consensus redefined by structures of PKI-type and Rev-type nuclear export signals bound to CRM1. Nat Struct Mol Biol. 2010;17:1367-76.

23. Dong X, Biswas A, Chook YM. Structural basis for assembly and disassembly of the CRM1 nuclear export complex. Nat Struct Mol Biol. 2009;16:558-60.

24. Dong X, Biswas A, Süel KE, Jackson LK, Martinez R, Gu H, et al. Structural basis for leucine-rich nuclear export signal recognition by CRM1. Nature. 2009; 458:1136-41.

25. Koyama M, Matsuura Y. An allosteric mechanism to displace nuclear export cargo from CRM1 and RanGTP by RanBP1. EMBO J. 2010;29:2002-13.

26. Taylor J, Sendino M, Gorelick AN, Pastore A, Chang MT, Penson AV, et al. Altered nuclear export signal recognition as a driver of oncogenesis. Cancer Discov. 2019:9:1452-67.

27. Walker JS, Hing ZA, Harrington B, Baumhardt J, Ozer HG, Lehman A, et al. Recurrent XPO1 mutations alter pathogenesis of chronic lymphocytic leukemia. J Hematol Oncol. 2021;14:1-21.

28. Jardin F, Pujals A, Pelletier L, Bohers E, Camus V, Mareschal S, et al. Recurrent mutations of the exportin 1 gene (XPO1) and their impact on selective inhibitor of nuclear export compounds sensitivity in primary mediastinal B-cell lymphoma. Am J Hematol. 2016;91:923-30.

29. Camus V, Miloudi H, Taly A, Sola B, Jardin F. XPO1 in B cell hematological malignancies: from recurrent somatic mutations to targeted therapy. J Hematol Oncol. 2017;10:1-13.

30. Newlands E, Rustin G, Brampton M. Phase I trial of elactocin. Br J Cancer. 1996;74:648-9.

31. Grosicki S, Simonova M, Spicka I, Pour L, Kriachok I, Gavriatopoulou M, et al. Once-per-week selinexor, bortezomib, and dexamethasone versus twice-perweek bortezomib and dexamethasone in patients with multiple myeloma (BOSTON): a randomised, open-label, phase 3 trial. Lancet. 2020;396:1563-73.

32. Nishi K, Yoshida M, Fujiwara D, Nishikawa M, Horinouchi S, Beppu T. Leptomycin $B$ targets a regulatory cascade of $\mathrm{crm} 1$, a fission yeast nuclear protein, involved in control of higher order chromosome structure and gene expression. J Biol Chem. 1994;269:6320-4.

33. Kudo N, Wolff B, Sekimoto T, Schreiner EP, Yoneda Y, Yanagida M, et al. Leptomycin $\mathrm{B}$ inhibition of signal-mediated nuclear export by direct binding to CRM1. Exp Cell Res. 1998;242:540-7. 
34. Laín S, Xirodimas D, Lane DP. Accumulating active p53 in the nucleus by inhibition of nuclear export: a novel strategy to promote the p53 tumor suppressor function. Exp Cell Res. 1999;253:315-24.

35. Bonazzi S, Eidam O, Güttinger S, Wach JY, Zemp I, Kutay U, et al. Anguinomycins and derivatives: total syntheses, modeling, and biological evaluation of the inhibition of nucleocytoplasmic transport. J Am Chem Soc. 2010;132:1432-42.

36. Köster M, Lykke-Andersen S, Elnakady YA, Gerth K, Washausen P, Höfle G, et al. Ratjadones inhibit nuclear export by blocking CRM1/exportin 1. Exp Cell Res. 2003;286:321-31.

37. Kalid O, Toledo Warshaviak D, Shechter S, Sherman W, Shacham S. Consensus induced fit docking (cIFD): methodology, validation, and application to the discovery of novel Crm1 inhibitors. J Comput Aided Mol Des. 2012;26:1217-28.

38. Senapedis WT, Baloglu E, Landesman Y. Clinical translation of nuclear export inhibitors in cancer. Semin Cancer Biol. 2014; 2014:74-86.

39. Etchin J, Berezovskaya A, Conway A, Galinsky I, Stone R, Baloglu E, et al. KPT8602, a second-generation inhibitor of XPO1-mediated nuclear export, is well tolerated and highly active against AML blasts and leukemia-initiating cells. Leukemia. 2017;31:143-50.

40. Tabe Y, Kojima K, Yamamoto S, Sekihara K, Matsushita H, Davis RE, et al. Ribosomal biogenesis and translational flux inhibition by the selective inhibitor of nuclear export (SINE) XPO1 antagonist KPT-185. PLoS ONE. 2015;10:e0137210.

41. Sadowski AR, Gardner HL, Borgatti A, Wilson H, Vail DM, Lachowicz J, et al. Phase II study of the oral selective inhibitor of nuclear export (SINE) KPT-335 (verdinexor) in dogs with lymphoma. BMC Vet Res. 2018;14:250.

42. Schmidt J, Braggio E, Kortuem K, Egan J, Zhu Y, Xin C, et al. Genome-wide studies in multiple myeloma identify XPO1/CRM1 as a critical target validated using the selective nuclear export inhibitor KPT-276. Leukemia. 2013;27:2357-65.

43. Gionco J, Chen J, Lindsay R, Macri V, Brooks CL. SL-401, a targeted therapy directed to the interleukin-3 receptor (CD123), and SL-801, a reversible inhibitor of exportin-1 (XPO1), display synergistic anti-tumor activity against hematologic malignancies in vitro. Am Soc Hematol. 2016;128:4724.

44. Wang J, Barve $M$, Chiorean E, LoRusso P, Courtney K, Qi D, et al. Interim results from trial of SL-801, a novel XPO-1 inhibitor, in patients with advanced solid tumours. Ann Oncol. 2019;30:v175.

45. Kubbutat $\mathrm{MH}$, Jones $\mathrm{SN}$, Vousden $\mathrm{KH}$. Regulation of p53 stability by Mdm2. Nature. 1997;387:299-303.

46. Döhner K, Schlenk RF, Habdank M, Scholl C, Rücker FG, Corbacioglu A, et al. Mutant nucleophosmin (NPM1) predicts favorable prognosis in younger adults with acute myeloid leukemia and normal cytogenetics: interaction with other gene mutations. Blood. 2005;106:3740-6.

47. Verhaak RG, Goudswaard CS, Van Putten W, Bijl MA, Sanders MA, Hugens W, et al. Mutations in nucleophosmin (NPM1) in acute myeloid leukemia (AML) association with other gene abnormalities and previously established gene expression signatures and their favorable prognostic significance. Blood. 2005:106:3747-54.

48. Gu X, Ebrahem Q, Mahfouz RZ, Hasipek M, Enane F, Radivoyevitch T, et al. Leukemogenic nucleophosmin mutation disrupts the transcription factor hub that regulates granulomonocytic fates. J Clin Investig. 2018;128:4260-79.

49. Garzon R, Savona M, Baz R, Andreeff M, Gabrail N, Gutierrez M, et al. A phase 1 clinical trial of single-agent selinexor in acute myeloid leukemia. Blood. 2017; 129:3165-74

50. Fiedler W, Chromik J, Amberg S, Kebenko M, Thol F, Schlipfenbacher V, et al. A Phase II study of selinexor plus cytarabine and idarubicin in patients with relapsed/refractory acute myeloid leukaemia. $\mathrm{Br} J$ Haematol. 2020;190: e169-e173.

51. Fiedler W, Heuser M, Chromik J, Thol F, Bokemeyer C, Theile $S$, et al. Phase II results of Ara-C and idarubicin in combination with the selective inhibitor of nuclear export (SINE) compound selinexor (KPT-330) in patients with relapsed or refractory AML. Blood. 2016;128:341

52. Klossowski S, Miao H, Kempinska K, Wu T, Purohit T, Kim E, et al. Menin inhibitor MI-3454 induces remission in MLL1-rearranged and NPM1-mutated models of leukemia. J Clin Investig. 2020;130:981-97.

53. Gandhi UH, Senapedis W, Baloglu E, Unger TJ, Chari A, Vogl D, et al. Clinical implications of targeting XPO1-mediated nuclear export in multiple myeloma. Clin Lymphoma Myeloma Leuk. 2018;18:335-45.

54. Carroll M, Borden KL. The oncogene elF4E: using biochemical insights to target cancer. J Interferon Cytokine Res. 2013;33:227-38.

55. Fischer MA, Friedlander SY, Arrate MP, Chang H, Gorska AE, Fuller LD, et al. Venetoclax response is enhanced by selective inhibitor of nuclear export compounds in hematologic malignancies. Blood Adv. 2020;4:586-98.

56. Schlenk RF, Kayser S, Bullinger L, Kobbe G, Casper J, Ringhoffer M, et al. Differential impact of allelic ratio and insertion site in FLT3-ITD-positive AML with respect to allogeneic transplantation. Blood. 2014;124:3441-9.
57. Meshinchi S, Woods WG, Stirewalt DL, Sweetser DA, Buckley JD, Tjoa TK, et al. Prevalence and prognostic significance of Flt3 internal tandem duplication in pediatric acute myeloid leukemia. Blood. 2001;97:89-94.

58. Zhang W, Ly C, Ishizawa J, Mu H, Ruvolo V, Shacham S, et al. Combinatorial targeting of XPO1 and FLT3 exerts synergistic anti-leukemia effects through induction of differentiation and apoptosis in FLT3-mutated acute myeloid leukemias: from concept to clinical trial. Haematologica. 2018;103:1642-53.

59. Taylor J, Mi X, Penson AV, Paffenholz SV, Alvarez K, Sigler A, et al. Safety and activity of selinexor in patients with myelodysplastic syndromes or oligoblastic acute myeloid leukaemia refractory to hypomethylating agents: a single-centre, single-arm, phase 2 trial. Lancet Haematol. 2020;7:e566-e574.

60. Ranganathan P, Yu X, Santhanam R, Hofstetter J, Walker A, Walsh K, et al. Decitabine priming enhances the antileukemic effects of exportin 1 (XPO1) selective inhibitor selinexor in acute myeloid leukemia. Blood. 2015; 125:2689-92.

61. Vigneri $P$, Wang JY. Induction of apoptosis in chronic myelogenous leukemia cells through nuclear entrapment of BCR-ABL tyrosine kinase. Nat Med. 2001;7:228-34.

62. Aloisi A, Di Gregorio S, Stagno F, Guglielmo P, Mannino F, Sormani MP, et al. $B C R-A B L$ nuclear entrapment kills human CML cells: ex vivo study on 35 patients with the combination of imatinib mesylate and leptomycin B. Blood. 2006;107:1591-8.

63. Chanukuppa V, Paul D, Taunk K, Chatterjee T, Sharma S, Kumar S, et al. XPO1 is a critical player for bortezomib resistance in multiple myeloma: a quantitative proteomic approach. J Proteom. 2019;209:103504.

64. Turner JG, Kashyap T, Dawson JL, Gomez J, Bauer AA, Grant S, et al. XPO1 inhibitor combination therapy with bortezomib or carfilzomib induces nuclear localization of IKBa and overcomes acquired proteasome inhibitor resistance in human multiple myeloma. Oncotarget. 2016;7:78896-909.

65. Ranganathan P, Kashyap T, Yu X, Meng X, Lai T-H, McNeil B, et al. XPO1 inhibition using selinexor synergizes with chemotherapy in acute myeloid leukemia by targeting DNA repair and restoring topoisomerase lla to the nucleus. Clin Cancer Res. 2016;22:6142-52.

66. Saenz-Ponce N, Pillay R, de Long LM, Kashyap T, Argueta C, Landesman Y, et al. Targeting the XPO1-dependent nuclear export of E2F7 reverses anthracycline resistance in head and neck squamous cell carcinomas. Sci Transl Med. 2018;10: eaar7223.

67. Hing ZA, Mantel R, Beckwith KA, Guinn D, Williams E, Smith LL, et al. Selinexor is effective in acquired resistance to ibrutinib and synergizes with ibrutinib in chronic lymphocytic leukemia. Blood. 2015;125:3128-32.

68. Kapoor I, Li Y, Sharma A, Zhu H, Bodo J, Xu W, et al. Resistance to BTK inhibition by ibrutinib can be overcome by preventing FOXO3a nuclear export and $\mathrm{PI} 3 \mathrm{~K}$ / AKT activation in B-cell lymphoid malignancies. Cell Death Dis. 2019;10:924.

69. Ming M, Wu W, Xie B, Sukhanova M, Wang W, Kadri S, et al. XPO1 inhibitor selinexor overcomes intrinsic ibrutinib resistance in mantle cell lymphoma via nuclear retention of IKB. Mol Cancer Ther. 2018;17:2564-74.

70. Bhatnagar B, Zhao Q, Mims AS, Vasu S, Behbehani GK, Larkin K, et al. Selinexor in combination with decitabine in patients with acute myeloid leukemia: results from a phase 1 study. Leuk Lymphoma. 2020;61:387-96.

71. Wang AY, Weiner $H$, Green $M$, Chang $H$, Fulton $N$, Larson RA, et al. A phase study of selinexor in combination with high-dose cytarabine and mitoxantrone for remission induction in patients with acute myeloid leukemia. J Hematol Oncol. 2018;11:1-10.

72. Rubnitz JE, Kaufman R, Ribeiro RC, Klebanov B, Ellis J, Landesman Y, et al. Phase study of Selinexor, a selective inhibitor of nuclear export, in combination with Fludarabine and Cytarabine in pediatric patients with relapsed or refractory AML. J Clin Oncol. 2015:34:4094-101.

73. Bhatnagar B, Walker AR, Mims AS, Vasu S, Klisovic RB, Behbehani G, et al. Phase 1 study of selinexor plus mitoxantrone, etoposide, and cytarabine in acute myeloid leukemia. J Clin Oncol. 2018;36:7048.

74. Sweet K, Komrokji R, Padron E, Cubitt CL, Turner JG, Zhou J, et al. Phase I clinical trial of selinexor in combination with daunorubicin and cytarabine in previously untreated poor-risk acute myeloid leukemia. Clin Cancer Res. 2020;26:54-60.

75. Østgård LSG, Medeiros BC, Sengeløv H, Nørgaard M, Andersen MK, Dufva IH et al. Epidemiology and clinical significance of secondary and therapy-related acute myeloid leukemia: a National Population-based Cohort Study. J Clin Oncol. 2015;33:3641-9.

76. Cooperrider JH, Fulton N, Artz AS, Larson RA, Stock W, Kosuri S, et al. Phase I trial of maintenance selinexor after allogeneic hematopoietic stem cell transplantation for patients with acute myeloid leukemia and myelodysplastic syndrome. Bone Marrow Transpl. 2020:55:1-3.

77. Gisselbrecht C, Schmitz N, Mounier N, Gill DS, Linch DC, Trneny M, et al. Rituximab maintenance therapy after autologous stem-cell transplantation in patients with relapsed CD20+ diffuse large B-cell lymphoma: final analysis of 
the collaborative trial in relapsed aggressive lymphoma. J Clin Oncol. 2012;30:4462.

78. Crump M, Neelapu SS, Farooq U, Van Den Neste E, Kuruvilla J, Westin J, et al. Outcomes in refractory diffuse large B-cell lymphoma: results from the international SCHOLAR-1 study. Blood. 2017;130:1800-8.

79. Kuruvilla J, Savona M, Baz R, Mau-Sorensen PM, Gabrail N, Garzon R, et al. Selective inhibition of nuclear export with selinexor in patients with nonHodgkin lymphoma. Blood. 2017;129:3175-83.

80. Kalakonda N, Maerevoet M, Cavallo F, Follows G, Goy A, Vermaat JS, et al. Selinexor in patients with relapsed or refractory diffuse large B-cell lymphoma (SADAL): a single-arm, multinational, multicentre, open-label, phase 2 trial. Lancet Haematol. 2020;7:e511-e522.

81. Maerevoet M, Westin J, Thieblemont C, Zijlstra J, Hill BT, Vicente FDLC, et al. Abstract CT132: a phase $2 \mathrm{~b}$ randomized study of selinexor in patients with relapsed/refractory diffuse large B-cell lymphoma (DLBCL) demonstrates durable responses in both GCB \& non-GCB subtypes. Philadelphia: AACR; 2017.

82. Stephens DM, Huang $Y$, Agyeman A, Ruppert AS, Hu B, Turner N, et al. Selinexor combined with Ibrutinib demonstrates tolerability and efficacy in advanced B-cell malignancies: a phase I study. Washington: American Society of Hematology; 2019.

83. Seymour EK, Khan HY, Li Y, Chaker M, Muqbil I, Aboukameel A, et al. Selinexor in combination with R-CHOP for frontline treatment of Non-Hodgkin lymphoma: results of a phase I study. Clin Cancer Res. 2021;27:3307-16.

84. Chen C, Siegel D, Gutierrez M, Jacoby M, Hofmeister CC, Gabrail N, et al. Safety and efficacy of selinexor in relapsed or refractory multiple myeloma and Waldenstrom macroglobulinemia. Blood. 2018;131:855-63.

85. San Miguel J, Weisel K, Moreau P, Lacy M, Song K, Delforge M, et al. Pomalidomide plus low-dose dexamethasone versus high-dose dexamethasone alone for patients with relapsed and refractory multiple myeloma (MM-003): a randomised, open-label, phase 3 trial. Lancet Oncol. 2013;14:1055-66.

86. Argueta C, Kashyap T, Klebanov B, Chang H, Friedlander S, Baloglu E, et al. Selinexor or KPT-8602 mediated XPO1 inhibition synergizes with dexamethasone to repress convergent pathways in the MTORC1 signaling network and drive cell death in multiple myeloma. Cancer Res. 2017;77:329.

87. Argueta C, Kashyap T, Klebanov B, Unger TJ, Guo C, Harrington S, et al. Selinexor synergizes with dexamethasone to repress $\mathrm{mTORC1}$ signaling and induce multiple myeloma cell death. Oncotarget. 2018;9:25529.

88. Vogl DT, Dingli D, Cornell RF, Huff CA, Jagannath S, Bhutani D, et al. Selective inhibition of nuclear export with oral selinexor for treatment of relapsed or refractory multiple myeloma. J Clin Oncol. 2018;36:859-66.

89. Chari A, Vogl DT, Gavriatopoulou M, Nooka AK, Yee AJ, Huff CA, et al. Oral selinexor-dexamethasone for triple-class refractory multiple myeloma. $\mathrm{N}$ Engl J Med. 2019;381:727-38.

90. Yee AJ, Huff CA, Chari A, Vogl DT, Gavriatopoulou M, Nooka AK, et al. Response to therapy and the effectiveness of treatment with selinexor and dexamethasone in patients with penta-exposed triple-class refractory myeloma who had plasmacytomas. Washington: American Society of Hematology; 2019.

91. Bahlis NJ, Sutherland H, White D, Sebag M, Lentzsch S, Kotb R, et al. Selinexor plus low-dose bortezomib and dexamethasone for patients with relapsed or refractory multiple myeloma. Blood. 2018;132:2546-54.

92. Haines JD, Herbin O, De La Hera B, Vidaurre OG, Moy GA, Sun Q, et al. Nuclear export inhibitors avert progression in preclinical models of inflammatory demyelination. Nat Neurosci. 2015;18:511-20.

93. Jakubowiak AJ, Jasielec JK, Rosenbaum CA, Cole CE, Chari A, Mikhael J, et al. Phase 1 study of selinexor plus carfilzomib and dexamethasone for the treatment of relapsed/refractory multiple myeloma. Br J Haematol. 2019;186:549-60.

94. Gasparetto C, Lentzsch S, Schiller G, Callander N, Tuchman S, Chen C, et al. Selinexor, daratumumab, and dexamethasone in patients with relapsed or refractory multiple myeloma. eJHaem. 2021;2:56-65.

95. Daver N, Assi R, Ravandi F, Garcia-Manero G, Jabbour E, DiNardo CD, et al. A Phase I/II study of selinexor (SEL) with sorafenib in patients (pts) with relapsed and/or refractory (R/R) FLT3 mutated acute myeloid leukemia (AML). Clin Lymphoma Myeloma Leuk. 2017;17:S7-S8.

96. Lee S, Bhatnagar B, Mohan SR, Senapedis Jr WT, Baloglu E, Wang H, et al. Eltanexor (KPT-8602), a second-generation selective inhibitor of nuclear export (SINE) compound, in patients with higher-risk myelodysplastic syndrome. Washington: American Society of Hematology; 2019.

97. Abeykoon JP, Wu X, Nowakowski KE, Dasari S, Paludo J, Weroha SJ, et al. Salicylates enhance CRM1 inhibitor antitumor activity by induction of S-phase arrest and impairment of DNA-damage repair. Blood. 2021;137:513-23.

98. Seiler M, Yoshimi A, Darman R, Chan B, Keaney G, Thomas M, et al. H3B-8800, an orally available small-molecule splicing modulator, induces lethality in spliceosome-mutant cancers. Nat Med. 2018;24:497-504.
99. Steensma DP, Wermke M, Klimek VM, Greenberg PL, Font P, Komrokji RS, et al. Results of a clinical trial of H3B-8800, a splicing modulator, in patients with myelodysplastic syndromes (MDS), acute myeloid leukemia (AML) or chronic myelomonocytic leukemia (CMML). Washington: American Society of Hematology; 2019.

100. Pardee TS, Pladna KM, Lyerly $S$, Dralle $S$, Manuel M, Ellis LR, et al. Frontline selinexor and chemotherapy is highly active in older adults with acute myeloid leukemia (AML). Blood. 2020;136:24-25.

101. Baz RC, Shain KH, Alsina M, Brayer J, Rashal T, Cooksey JL, et al. Phase I trial of the combination of selinexor (SEL), liposomal doxorubicin (DOX) and dexamethasone (Dex) for relapsed and refractory multiple myeloma (RRMM). J Clin Oncol. 2016;34:8013-8013.

102. Cornell RF, Rossi AC, Baz R, Hofmeister C, Shustik C, Richter J, et al. Eltanexor (KPT-8602), a second-generation selective inhibitor of nuclear export (SINE) compound, in patients with refractory multiple myeloma. Blood. 2017;130:3134-3134

\section{ACKNOWLEDGEMENTS}

Figures 1A, 2 and 3 were created using Biorender.com. We thank Dr. Jeffrey Zonder for proof reading the article.

\section{AUTHOR CONTRIBUTIONS}

S. K. B.: Conception and design of the study, acquisition, analysis and interpretation of relevant studies, drafting the article and revising it critically for important intellectual content and final approval of the version. A. S. A.: Conception and design of the study, Drafting the article or revising it critically for important intellectual content, final approval of the version. Jaroslaw Maciejewski: Conception and design of the study, Drafting the article or revising it critically for important intellectual content, final approval of the version

\section{COMPETING INTERESTS}

ASA has acted as a consultant of GLG Consulting and GuidePoint, has received research grants from EISAI Janssen and Rhizen, and has been a speaker at an event organized by Karyopharm. The primary author's institution has received research funding (partially supporting the phase lb/Il studies NCT02178436 and NCT03147885) from Karyopharm. No other conflict of interest pertaining to this paper from all the authors.

\section{ADDITIONAL INFORMATION}

Supplementary information The online version contains supplementary material available at https://doi.org/10.1038/s41375-021-01483-z.

Correspondence and requests for materials should be addressed to Jaroslaw Maciejewski.

Reprints and permission information is available at http://www.nature.com/ reprints

Publisher's note Springer Nature remains neutral with regard to jurisdictional claims in published maps and institutional affiliations.

Open Access This article is licensed under a Creative Commons Attribution 4.0 International License, which permits use, sharing, adaptation, distribution and reproduction in any medium or format, as long as you give appropriate credit to the original author(s) and the source, provide a link to the Creative Commons license, and indicate if changes were made. The images or other third party material in this article are included in the article's Creative Commons license, unless indicated otherwise in a credit line to the material. If material is not included in the article's Creative Commons license and your intended use is not permitted by statutory regulation or exceeds the permitted use, you will need to obtain permission directly from the copyright holder. To view a copy of this license, visit http://creativecommons. org/licenses/by/4.0/

(c) The Author(s) 2021 